\title{
Psychological Dimension of HIV/AIDS and Recent Advances in
}

\section{Its Management}

Anurag Agrawal ${ }^{1}$, Meha Jain ${ }^{2}$, Shikha Agrawal ${ }^{3}$, Shweta Singh ${ }^{4}$, Mamta Yadav $^{5}$

\section{ABSTRACT}

HIV as a chronic illness is manageable but not curable. Psychiatric disorders not only act as risk factors for HIV infection but also result from the diagnosis of HIV infection. The psychiatric disorders range from anxiety, depression to neurocognitive disorders. The diagnosis also means psychological and emotional effects on the patients and the caregivers. This requires that biopsychosocial perspective be employed in managing such patients for better treatment adherence and increased quality of life. There are various psychological interventions available like cognitive behavior therapy, group therapy, mindfulness based therapy etc. Despite wide prevalence of such problems present in India, very few clinicians are aware of these psychological interventions and make them available to the patients.

Keywords: HIV/ AIDS, Mental illness, psychological interventions

Chronic illness is a long-lasting condition that can be controlled but not cured. Arthritis, cancer, asthma, diabetes, cardio vascular disease, HIV/AIDS are commonly occurring chronic illnesses. HIV is a unique type of virus (a retrovirus) which invades the helper T cells (CD4 cells) in the body of the host. It is preventable, manageable but not curable. It is in Stage IV when the immune system weakens and the illnesses become more severe leading to an AIDS diagnosis.

There are around 34 million people living with HIV. In 2011 there were around 2.5 million new HIV infections and 1.7 million deaths due to AIDS (WHO, June 2011). The adult HIV prevalence in India has increased to 0.27 percent, as of 2011 (NACO, 2013) and it was estimated that 2.4 million people were living with HIV in India (UNAIDS, 2010).

Studies have shown that there is relationship between HIV transmission and mental illness and that prevalence of psychiatric disorders is higher in HIV infected individuals than the general

\footnotetext{
${ }^{1}$ Assistant Professor, Department of Psychiatry, I.I.M.S. \& R., Lucknow, UP.

${ }^{2}$ Child Psychologist, Department of Pediatrics, I.I.M.S. \& R., Lucknow, UP.

${ }^{3}$ Senior Resident, Department of Ophthalmology, I.I.M.S. \& R., Lucknow, UP.

${ }^{4}$ Assistant Professor, Department of Psychiatry, King George’s Medical University, Lucknow, UP.

${ }^{5}$ Clinical Psychologist, Department of Psychiatry, I.I.M.S. \& R., Lucknow, UP. (C) 2015 I A Agrawal, M Jain, S Agrawal, S Singh, M Yadav; licensee IJIP. This is an Open Access Research distributed under the terms of the Creative Commons Attribution License (http://creativecommons.org/licenses/by/2.0), which permits unrestricted use, distribution, and reproduction in any Medium, provided the original work is properly cited.
} 


\section{Psychological Dimension of HIV/AIDS and Recent Advances in Its Management}

population. There are several ways in which HIV infection and psychiatric disorders are linked. (i) HIV infection owing to its malignant course and the associated stigma often results in emotional reactions of a serious nature among those infected. (ii) The HIV has direct effects on the brain that may lead to neurocognitive disturbances, psychosis or behavioural changes. (iii) Opportunistic neurological and systemic infections and their treatment may lead to neuropsychiatric problems. (iv) Some of the drugs used in HAART (highly active antiretroviral therapy) are known to be associated with psychiatric side effects. (v) Persons with severe mental illness are known to be vulnerable to HIV infection and there are special management concerns in this population. (vi) Substance abuse and HIV are linked in direct ways (intravenous drug use: IVDU) and in indirect ways by their influence on sexual behaviour. (vii) Treatment adherence and course of illness have been found to be influenced by emotional factors and substance use (Chandra et al., 2005).

Thus it is important to treat HIV with biopsychosocial perspective in mind with special emphasis on recognizing and managing psychological problems during routine assessment and management of medical problems. Recent advances have shown that focussed counselling, cognitive behaviour therapy, group therapy, mindfulness based therapy etc. along with medical treatment can lead to better outcome. Through therapy psychosocial issues are addressed, patients' journey through life review and life closure issues, along with grief, anger, guilt, relationship difficulties and resolution of 'unfinished business.'

\section{PSYCHIATRIC DISORDERS AND HIV}

\section{Substance use}

Research shows that 20 to 73 percent of HIV/AIDS infected individuals have substance abuse disorders (Gallego et al., 2000). Alcohol abuse increases the probability of a variety of risky sexual behaviors, including sex with multiple partners, sex with strangers, possibility of rape, failure to use condoms, and sex with intravenous drug user.

\section{Schizophrenia}

People with schizophrenia, who have sex, do appear to be more likely to engage in known highrisk sexual behaviours. In a study by Cournos et al. (1993) condom use was very low (around 8\%), drug or alcohol use during sex was common, as was sexual exchange (for money, drugs or other goods. In a recent population based cohort study it was found that HIV was associated with an increased risk of schizophrenia especially in those with substance use disorder (Helleberg et al., 2015).

\section{Personality disorder}

HIV/AIDS patients who tend toward instability and extroversion exhibit a higher level of risky behavior (Treisman, 2001). People with antisocial personality are at increased risk of exposure to HIV, especially in the context of drug-taking (Compton et al. 1995) as they are: more prone to 
share needle, more likely to have higher number of lifetime sexual problems, more likely to engage in unprotected anal sex.

\section{HIV/ AIDS AND PSYCHIATRIC DISORDERS}

30-60\% lifetime prevalence of psychiatric disorders has been reported in HIV patients (Atkinson et al.,1988; Morrison et al 2002). Higher prevalence of psychiatric disorders was found in patients with HIV as compared to the general population (Ahuja et al., 1998).

\begin{tabular}{|c|c|}
\hline Stages & Disorder \\
\hline Stage I & $\begin{array}{ll}\text { - } & \text { Acute stress reaction } \\
\text { - } & \text { Adjustment } \\
& \text { disorders } \\
\text { - } & \text { Panic disorders } \\
\text { - } & \text { Suicide }\end{array}$ \\
\hline Stage II & $\begin{array}{ll}\text { - } & \text { Depression } \\
\text { - } & \text { Substance abuse } \\
\text { - } & \text { Anxiety disorders } \\
\text { - } & \text { Personality changes } \\
\text { - } & \text { Suicide }\end{array}$ \\
\hline Stage III and IV & $\begin{array}{ll}\text { - } & \text { Dementia } \\
\text { - } & \text { Delirium } \\
\text { - } & \text { Psychosis } \\
\text { - } & \text { Mania } \\
\text { - } & \text { Depression } \\
\text { - } & \text { Seizures }\end{array}$ \\
\hline
\end{tabular}

\section{'AIDS' phobia}

It is the fear of contracting HIV infection, despite the negative test results. Patients with hypochondrias are or OCD may present with a fear of developing / having AIDS as a complaint. Sometimes, this is related to guilt over unprotected intercourse, misinformation and inadequate knowledge. It has been associated with anxious temperament and is more among those with health anxiety.

\section{Grief and bereavement}

Maladaptive grief shows more rapid decline of CD4 (Goforth et al, 2009). Bereavement may result due to: severity of HIV and AIDS, the loss of health, a decrease in functioning, the 


\section{Psychological Dimension of HIV/AIDS and Recent Advances in Its Management}

deterioration of body integrity, the anticipatory loss of life may also result. The bereaved person typically considers symptoms of sadness, insomnia, poor appetite, and weight loss.

\section{Anxiety disorders}

Depression and anxiety disorders are seen throughout the course of HIV infection, and the conditions commonly coexist. Prevalence of anxiety disorder ranges from 5\%-40\% (McDaniel and Blalock, 2000). The anxiety disorders which are commonly found in such patients are adjustment disorders, acute stress reaction, panic disorder, obsessive compulsive disorder and generalized anxiety disorder (GAD). Prevalence of GAD is increased in HIV infected individuals as compared to HIV negative individuals (Hinkin et al., 2001). PTSD can develop in response to HIV diagnosis with diagnosis of potentially life threatening illnesses (Kelly et al., 1998).

\section{Depression}

In the study on prevalence of psychopathology 36\% of the patients tested positive for major depression and 27\% for dysthymia (Bing et al., 2001). There has been found increase in depression in HIV infected individuals in recent studies (Nakimuli, 2011) Depression has a negative impact on adherence with medical treatment, quality of life and treatment outcome. HIV increases the risk of developing major depression through direct injury to subcortical areas of brain, chronic stress, worsening social isolation and intense demoralization.

\section{Mania}

Mania can occur in conjunction with bipolar disorder or HIV infection of the brain. Mania occurring early is likely to be due to an underlying bipolar disorder. Mania occurring late in the course of illness ("AIDS mania”) is probably due to HIV infection of the brain.

The prevalence of mania is reported to be significantly increased in patients with AIDS compared to the general population (Lyketsos et al., 1993; Ellen et al., 1998).

HIV-associated mania is different from mania with bipolar disorder: more irritability, less hyper talkativeness, more psychomotor slowing and cognitive impairment

\section{Psychosis}

Psychotic symptoms can appear as a part of delirium, dementia or any other organic brain syndrome. Drug-induced psychosis is a common cause. $0.2 \%-15 \%$ of patients with HAD develop psychotic symptoms (Sewell, 1996)

\section{HIV associated neuro-cognitive disorders (HAND)}

There is high prevalence of milder forms (HIV-associated asymptomatic neurocognitive impairment (ANI) and HIV-1-associated mild neurocognitive disorder (MND) in patients treated with combination antiretroviral therapy (Heaton et al., 2010). Highly active antiretroviral therapy (HAART) substantially decreases the occurrence of dementia. 


\section{Psychological Dimension of HIV/AIDS and Recent Advances in Its Management}

\section{Delirium}

30 to 40 percent of hospitalized patients with human immunodeficiency virus (HIV) infection develop delirium (Perry, 1990). HIV increases chances of delirium (Sonneville, 2011). It has a high mortality rate and requires immediate treatment. It is characterized by: inattention, disorganized thinking or confusion, fluctuations in levels of consciousness, presence of emotional changes and hallucinations and delusions.

\section{Sleep disorder}

Studies have found high sleep disturbances among HIV infected persons (Reid et al., 2005; Crum-Cianflone et al., 2012). Sleep disturbances have been noted to appear soon after initial HIV infection and continue throughout the course of the disease (Cruess, et al., 2003).

\section{Suicide}

A study by Chandra et al., 1998 revealed persistent suicidal ideations in 14 per cent, death wishes in 20 per cent and suicidal attempts in 8 per cent HIV patients (Chandra et al., 1998). Suicide rates are found to be 10 times higher as compared to general population (Catalan et al., 2011). Suicidal behaviors in PLWH may be associated with an initial HIV or AIDS diagnosis, advancing disease, symptoms of illness, psychiatric disorders, and substance use (Kelly et al., 1998). Suicidality may be the direct physiological result of HIV or a reaction to chronic pain, or an emotional reaction to having a chronic and life-threatening illness.

\section{Psychiatric side effects of anti retroviral drugs}

Antiretroviral drugs are associated with significant side effects. cohorts, clinical studies have shown that there are CNS side effects of efavirenz (Rih et al., 2006). It has been seen that up to $50 \%$ of patients in clinical studies experience dizziness, headache, confusion, impaired concentration, and abnormal or vivid dreams which usually resolve in 2-4 weeks. Case reports have shown Zidovudine causes mania, depression, insomnia, headaches and Nevirapine \& Abacavir: can cause psychosis.

\section{MANAGEMENT}

Combined Pharmacological and psychological interventions are both important in these patients to deal with mental health problems. Psychological interventions focus on the individual as well as the caregivers. It deals with the symptoms like depression; anxiety etc. and helps the client and family in dealing with the emotional reactions to the diagnosis. Better mental health may in turn lead to reduction in risk behaviours and improvement in HIV treatment adherence which eventually increases their quality of life (Sikkema et al., 2010).

Intervention is done at three levels: primary intervention, secondary intervention and tertiary intervention. Primary intervention includes changing social structures and increasing knowledge, information and communication. Secondary intervention includes recognizing mental disorder risk factors, including mental health in primary health care, providing access to psychiatric 


\section{Psychological Dimension of HIV/AIDS and Recent Advances in Its Management}

medications and providing access to antiretroviral drug treatment. Tertiary intervention includes improving communication between parents and children, preparing children for life after parental death, training teachers to offer support and additional measures for easing transitions.

\section{COUNSELING}

Counseling for HIV patients should be specialized and done by trained individuals as the diagnosis of infection results in various emotional reactions like fear, denial, anger, loss, grief, anxiety etc. it is not only the clients who go through this but also their close social networks who experience the same reactions. The process of counseling is confidential. It should be empowering and help the clients take decisions that will affect not only their life but also the life of their family members. The counseling is done before and after the client is screened.

\section{Pre test counselling}

This is done before the client is screened to provide education as well as guidance to the client. The main aim is to discuss the meaning of a positive or negative result and clarify distortions, give emotional support, explore high-risk behaviors and recommend risk-reducing interventions. The client is told about confidentiality and that their results will not be discussed with anyone without their permission. It also addresses the potential impact of the result on social status (e.g., health and life insurance coverage, employment, housing)

\section{Post test counselling}

It is done just after the test has been done. It aims to provide interpretation of test result and clarify distortion. If test is negative recommendations are given for prevention of transmission (careful discussion of high-risk behaviours and guidelines for prevention and transmission)

If test result is positive, recommendations against donating blood, sperm, or organs and against sharing razors, toothbrushes, and anything that may have blood on it. Referral is made for appropriate psychological support: HIV-positive patients often need access to a mental health team. Common themes include the shock of the diagnosis, the fear of death, and social consequences, grief over potential loss, and dashed hopes for good news. The counselor also needs to look for depression, hopelessness, anger, frustration, guilt, and obsessional themes.

\section{Cognitive behavior therapy}

Cognitive behavioural therapy has a good evidence base in the treatment of depression in people suffering from chronic and life-threatening diseases. Cognitive behavioural therapy has been shown to improve adherence to prescribed medication in chronic medical disorders like multiple sclerosis (Mohr, 2000).

In a study by Safren, 2012, found that in patients managing multiple challenges including HIV, depression, substance dependence, and adherence, CBT-AD is a useful way to integrate treatment of depression with an adherence intervention (Safren, 2012). 


\section{Psychological Dimension of HIV/AIDS and Recent Advances in Its Management}

In the therapy the start of session includes an assessment and discussion of HIV medication adherence and current mood. Motivational interviewing and psycho education is to be done next. Activity scheduling, problem solving training and relaxation and diaphragmatic breathing are the other steps.

\section{Group therapy}

Group interventions provide a range of therapeutic processes, both general and specific (Burlingame et al., 1995). Groups offer a forum for peer support, a sense of universalism or shared experience, and an opportunity to learn from others facing similar challenge. Peer support and modeling contributes to new coping resources and self efficacy (Fawzy et al., 1996). A support group has the beneficial effect of moderating the patient's sense of isolation by providing a new social network.

\section{Supportive-expressive group therapy}

Each supportive-expressive therapy group is led by two therapists. The therapist should have training and experience in psychotherapy or group therapy, as well as training and experience in psychosocial support for patients with life-threatening illnesses or medical management of HIV disease. He should also have at least minimal knowledge of HIV infection, medical complications and treatments, as well as treatment side effects. He should also have the ability to establish and maintain rapport, instill confidence in his or her ability, and display appropriate warmth and caring.

The goals of the therapy is to facilitate mutual support among group members and reduce isolation and improve social and family support/ decrease feelings of loneliness and guilt. The therapy promotes greater openness and emotional expressiveness both within and outside the group and facilitates the integration of a changed self and body image into the patient's current view of self. It also aims to improve coping skills and normalization of experiences, detoxify feelings around death and dying, help patients develop a life project, promote safer sexual practices, and enhance quality of life and greater authenticity.

In a study on older adults with HIV it was found that tele-supportive expressive group therapy reduces more depressive symptoms as compared to a standard of care at post intervention and at 4 and 8 month follow up (Timothy et al., 2013)

\section{Guided imagery}

It is a mind-body technique involving the deliberate prompting of mental images, used in the treatment of mental disorders, for performance enhancement, and in helping patients cope with diseases and their symptoms.

In a study by Simonton et al., 1978 surprising results were found in terms of unexpected longevity and improved immune activity as a result of relaxation techniques and imagery 


\section{Psychological Dimension of HIV/AIDS and Recent Advances in Its Management}

(Simonton et al., 1978). In a study including bi-weekly sessions of biofeedback/progressive muscle relaxation, hypnosis and meditation found improvement in the immunity in patients with HIV (Taylor, 1995).

\section{Acceptance based behavior therapy}

HIV/ AIDS patients tend to employ avoidance based coping due to fear of stigmatization and judgement. Avoidance-based coping is associated with lower adherence (Amir, 1997) and higher levels of distress (Thompson et al., 1992).

Acceptance based behavior therapy (ABBT) fosters the ability to accept distressing subjective experiences (thoughts, feelings, sensations, memories, etc.) without efforts to avoid, escape, or otherwise change the content of such experiences.

A pilot study was done by Moitra, 2011 to see the effect of ABBT to increase HAART adherence in HIV patients and found positive results in this regard (Moitra et al., 2011).

\section{Art therapy}

It is based on the belief that the creative process involved in the making of art is healing (Nainis et al., 2006). It lowers stress and gives patients an alternative focus other than their illness (Malchiodi, 1998). Studies suggest that art therapy can lead to increased awareness of self, as well as improved ability to cope with symptoms, stress, and traumatic experiences (American Art Therapy Association, 2003).

It may enhance the effects of pain medication through disassociating pain from psychological distress (Malchiodi, 1998). Hrenko (2005) found that art therapy was valuable for children diagnosed with HIV/AIDS in a therapeutic day camp. Another study found that art therapy was helpful for Native Americans living with HIV/AIDS who had difficulty articulating these emotions (Bien, 2005). In a study on HIV patients it was seen that one session art therapy resulted in improvement in symptoms associated with HIV/AIDS (Rao et al., 2009).

\section{Dance therapy}

Dance movement therapy (DMT) is a science and an art that involves the use of nonverbal communication through the medium of movement and dancing (Boris, 2002). Dance therapy provides an outlet for sadness, fear anger and joy (Levy, 1988). It has shown beneficial effects on immune functioning (Keller, 2002)). DMT enhances self esteem, greater social support and an increased sense of self control (Bojner et al., 2003) and a greater ability to cope with stressful life events (Kober, 1988)

A study by Fairfax et al., 2003 found that DMT has a positive impact on Quality of life of individuals with clients with co-occurring HIV, addiction, and mood disorders (Fairfax et al., 2003). 


\section{Psychological Dimension of HIV/AIDS and Recent Advances in Its Management}

\section{Music therapy}

Music therapy uses non-verbal communication as a mode of interacting and expressing of emotional states, and as the basis for developing a meaningful relationship (Ansdell, 1995; Pavlicevic,1997). It requires the implementation of a music intervention by a trained music therapist, the presence of a therapeutic process, and the use of personally tailored music experiences.

These music experiences include listening to live, therapist-composed, improvised, or pre recorded music; performing music on an instrument; improvising music spontaneously using voice or instruments, or both; composing music; and music combined with other modalities (e.g., movement, imagery, art) (Dileo 2007).

Studies have reported that music therapy was effective for enhancing spirituality (Wlodarczyk 2007), reducing tiredness and drowsiness (Horne-Thompson 2008), and alleviating discomfort and sadness (Nguyen 2003).

\section{Mindfulness based therapy}

Mindfulness-based interventions (MBIs) are focused on the cultivation of self-regulated attention, acceptance and openness to experiences gained through reflective structured exercises/practices like meditation or yoga. Most commonly used MBIs include mindfulnessbased stress reduction (MBSR) and cognitive therapy (MBCT). MBSR programs have been found to be effective in reducing stress and anxiety and have elicited positive physical outcomes in people living with HIV

An RCT with 76 participants compared MBSR to participants on a wait list and found reduced frequency, severity and distress from symptoms resulting from anti-retroviral therapy (ARTs) (Duncan et al., 2012).

Two small studies (one a RCT and one a pilot study) found that HIV positive participants receiving MBSR (Creswell et al., 2009) or practicing mindfulness meditation (Jam et al., 2010) over the course of 8 weeks stabilized or increased their CD4 counts.

Another RCT comparing MBSR to participants receiving treatment-as usual found that MBSR reduced avoidance and improved positive affect in HIV+ gay men who had previously reported difficulty in coping with their HIV and suffered from moderate to severe distress (Gayner, 2011). A study found MCBT as useful in reducing emotional disturbance symptoms (internalizing problems, depression, anxiety, hopelessness, and perceived stress) in HIV/ AIDS affected adolescents (Sinha, 2010). 


\section{Psychological Dimension of HIV/AIDS and Recent Advances in Its Management}

\section{CONCLUSION}

HIV is a chronic stressor that places HIV-infected persons as well as their immediate and extended families at risk for psychological distress and psychiatric disorders. The management should include both pharmacological and psychological interventions. The choice of therapy depends on the symptom to be focussed for eg. to increase adherence in HIV patients CBT-AD is a better choice. Recently mindfulness based therapies are being used in terminally ill patients with proven results. Thus, it can be said that a combination of therapies focusing on different symptoms can result in holistic improvement in the patient.

The reviews regarding psychological management were mainly from the western countries. In the past few decades a lot of work in India has been done in spreading awareness and reducing stigma in the patients of HIV as well as in the general population. Still there are gaps in dealing with psychological problems of these individuals. Pre and post test counselling has gained importance but proper skilled interventions for HIV patients is far from existence in India. Presently it is difficult to find skilled psychotherapist in setups dealing with HIV patients who can better deal with the psychological issues of these patients.

The researches now need to focus on the psychological interventions by skilled psychotherapists in HIV patients.

\section{REFERENCES}

Ahuja AS, Parkar SR, Yeolekar ME. (1998). Psychosocial aspects of seropositive HIV patients. J Assoc Physicians India;46:277-80. [PubMed]

American Art Therapy Association. (2007). www.artther apy.org Accessed June 1, 2007.

Amir, L. (1997). HIV infection in pregnant women in South Australia. Medical Journal of Australia, 166, 470-472.

Angela M. Fairfax T. (2003). Dance/movement Therapy Impact on Quality of Life in Clients with Co-occurring HIV, Addiction, and Mood Disorders. Drexel University, College of Nursing and Health Professions, Creative Arts in Therapy Program,

Ansdell, G. (1995). Music for life: Aspects of creative music therapy with adult clients. London: Jessica Kingsley Publishers.

Antinori A, Arendt G, Becker JT, Brew BJ, Byrd DA, Cherner M, Clifford DB,Cinque P, Epstein LG, Goodkin K,et al: Updated research nosology for HIV-associated neurocognitive disorders.Neurology2007, 69(18):1789-1799

Atkinson JH Jr, Grant I, Kennedy CJ, Richman DD, Spector SA, McCutchan JA. Prevalence of psychiatric disorders among men infected with human immunodeficiency virus: a controlled study. Arch Gen Psychiatry 1988;45(9):859-64.

Bien, M.B. (2005). Art therapy as emotional and spiritual medicine for Native Americans living with HIV/AIDS. Journal of Psychoactive Drugs, 37(3), 281292 


\section{Psychological Dimension of HIV/AIDS and Recent Advances in Its Management}

Bing EG, Burnam M, Longshore D, et al.: (2001). Psychiatric disorders and drug use among human immunodeficiency virus-infected adults in the United States. Arch Gen Psychiatry, 58:721-728

Bojner-Horwitz, E., Theorell, T. \& Anderberg, UM. (2003). Dance/movement therapy and changes in stress related hormones: A study of fibromyalgia patients with videointerpretation. The Arts in Psychotherapy, 30 (5), 255-264

Boris, R. (2002). The root of dance therapy: A consideration of movement, dancing and verbalisation vis-à-vis dance/movement therapy. New York: EBSCO.

Burlingame GM, Fuhriman A. Epilogue. In: Fuhriman A, Burlingame GM, eds. Handbook of Group Psychotherapy: An Empirical and Clinical Synthesis. New York: John Wiley \& Sons; 1994.

Catalan J, Harding R, Sibley E, et al. (2011). HIV infection and mental health: suicidal behaviour- systematic review. Psychol Health Med; 16(5): 588-611.

Chandra PS, Desai G, Ranjan S. (2005). HIV and psychiatric disorders. Indian J Med Res. ;121:451-67.

Chandra PS, Ravi V, Desai A. (1998). Anxiety and depression among HIV-infected heterosexuals- A report from India.J Psychosom Res; 45: 401-9

Compton, W.M., Cottler, L. B., Shillington, A.M., et al. (1995). Is antisocial personality disorder associated with increased HIV risk behaviors in cocaine users? Drug \& Alcohol Dependence, 37,3743.

Cournos F, McKinnon K, Meyer-Bahlburg H, Guido JR, Meyer I. (1993). HIV risk activity among persons with severe mental illness: Preliminary findings. Hospital and Community Psychiatry; 44: 1104-1106

Creswell JD, Myers HF, Cole SW, Irwin MR. (2009). Mindfulness meditation training effects on CD4+ T lympho-cytes in HIV-1 infected adults: A small randomized controlled trial.Brain, Behavior \& Immunity;23(2):184-8.

Cruess, D., Antoni, M., Gonzalex, J., Fletcher, M., Klinas, N., Duran, R., \& Ironson, G. (2003). Sleep disturbance mediates the association between psychological distress and immune status among HIV -positive men and women on combination antiretroviral therapy. Journal of Psychosomatic Research, 54, 185-189.

Crum-Cianflone NF, Roediger MP, Moore DJ, Hale B, Weintrob A, Ganesan A, Eberly LE, Johnson E, Agan BK, Letendre S. (2012). Prevalence and factors associated with sleep disturbances among early-treated HIV-infected persons. Clin Infect Dis. 2012 May;54(10):1485-94.

Dileo C, Bradt J. Music therapy: applications to stress management. In: Lehrer P, Woolfolk R editor(s). Principles and Practice of Stress Management. 3rd Edition. New York: Guilford Press, 2007

Duncan LG, Moskowitz JT, Neilands TB, Dilworth SE, Hecht FM, Johnson MO. (2012). Mindfulness-based stress reduction for HIV treatment side effects: A randomized, waitlist controlled trial. Journal of Pain and Symptom Management;43(2):161-71 


\section{Psychological Dimension of HIV/AIDS and Recent Advances in Its Management}

Edelman S, Bell DR, Kidman AD. A group cognitive behaviour therapy programme with metastatic breast cancer patients. Psycho-oncology 1999;8:295-305.

Ellen SR, Judd FK, Mijch AM, Cockram A. (1999). Secondary mania in patients with HIV infection. Aust New Zealand J Psychiatry; 33 : 353-60.

Fawzy FI, Fawzy NW, Wheeler JG. (1996). A post-hoc comparison of the efficiency of a psychoeducational intervention for melanoma patients delivered in group versus individual formats: an analysis of data from two studies. Psycho-Oncol; 5:81-89.

Gallego, Lucia, Victoria Gordillo, and Jose Catalan. (2000) "Psychiatric and Psychological Disorders associated to HIV Infection.” AIDS Reviews2, no. 1: 48-60.

Gayner B, Esplen MJ, Deroche P, Wong J, Bishop S, Kavanagh L, et al. (2011). A randomized controlled trial of mindfulness-based stress reduc-tion to manage affective symptoms and improve quality of life in gay men living with HIV. Journal of Behavioral Medicine;DOI: 10.1007/s10865-011-9350-8.

Goforth HW, Lowery J, Cutson TM, McMillan ES, Kenedi C, Cohen MA. (2009) Impact of bereavement on progression of AIDS and HIV infection: a review. Psychosomatics.;50(5):433-9. doi: 10.1176/appi.psy.50.5.433.

Heaton RK, Clifford DB, Franklin DR Jr, Woods SP, Ake C, Vaida F, Ellis RJ, Letendre SL, Marcotte TD, Atkinson JH,et al: (2010). HIV-associated neurocognitive disorders persist in the era of potent antiretroviral therapy: CHARTER Study. Neurology,75(23):20872096

Helleberg M. Pedersen MG. Pedersen CB, Mortensen PB. Obel N. (2015). Associations between HIV and schizophrenia and their effect on HIV treatment outcomes: a nationwide population-based cohort study in Denmark. The lancet HI; 2(8)

Hinkin CH, Castellon SA, Atkinson JH, Goodkin K. (2001). Neuropsychiatric aspects of HIV infection among older adults. J Clin Epidemiol;54 Suppl 1: S44-52

Horne-Thompson A, Grocke D. The effect of music therapy on anxiety in patients who are terminally ill. Journal of Palliative Care 2008;11(4):582-90.

Hrenko, K.D. (2005). Remembering camp dreamcatcher: Art therapy with children whose lives have been touched by HIV/AIDS. Art Therapy, 22(1), 3943.

Jam S, Imani AH, Foroughi M, SeyedAlinaghi S, Koochak HE, Mohraz M. (2010). The effects of mindful-ness-based stress reduction

Keller, S.L. (2002). Promoting wellness in persons with HIV infection. In. J.D. Durham \& F.R. Lashley (Eds), The person with HIv/Aids: Nursing perspectives (pp. 139-165). New York: Springer.

Kelly B, Raphael B, Judd F, Kernutt G, Burnett P, Burrows G. (1998). Posttraumatic stress disorder in response to HIV infection. Gen Hosp Psychiatry;20:345-52.

Kelly,B.,Raphael,B.,Judd,F.,Perdices,M.,Kernutt,G.,Burnett,P.,Dunne,M.,\&Burrows,G.(1998.)S uicidalideation,suicideattempts, andHIVinfection.Psychosomatics,39,405-415

Kober, G.D. (1988). Dance/Movement therapy in a Black rehabilitation ward: An exploratory study. Unpublished dissertation: Rand Afrikaans University. 


\section{Psychological Dimension of HIV/AIDS and Recent Advances in Its Management}

Levy, FJ. (1988). Dance movement therapy: A healing art. Reston, VA: American Alliance for Health, Physical Education, Recreation, and Dance.

Lyketsos CG, Hanson AL, Fishman M, Rosenblatt A, McHugh PR, Treisman GJ.. (1993). Manic syndrome early and late in the course of HIV. Am J Psychiatry; 150: 326-7.

Malchiodi, C.A. (1998).The art therapy sourcebook. Los Angeles: Lowell House

Mandal MC, Mullick SI, Nahar JS, Khanum M, Lahiry S, Islam MA. Prevalence of psychiatric ailments among patients with sexually transmitted disease. Mymensingh Med J. 2007;16:S23-7.[PubMed]

Mc Daniel, S.J., \& Blalock, A.C. (2000). Diagnosis and management of HIV-related mood and anxiety disorders. In new diresctions in psychiatric services (No. 87, pp. 51-56). San Francisco: Jossey Bass.

Mohr DC, Likosky W, Bertagnolli A, Goodkin DE, Van Der Wende J, Dwyer P, Dick LP. (2000). Telephone-administered cognitive-behavioral therapy for the treatment of depressive symptoms in multiple sclerosis. J Consult Clin Psychol. 2000 Apr;68(2):35661

Moitra E, Herbert JD, Forman EM. (2011). Acceptance-Based Behavior Therapy to Promote HIV Medication Adherence

Moitra E, Herbert JD, Forman EM. (2011). Acceptance-based behavior therapy to promote HIV medication adherence. AIDS Care. 23(12):1660-7.

Morrison MF, Petitto JM, Ten Hanc T, Gettes DR, Chiappini MS, Weber AL, et al. (2002). Depressive and anxiety disorders in women with HIV infection. Am J Psychiatry; 159: 789-96.

NACO (2013). India Annual Report 2012-13

Nainis, N., Paice, J.A., Ratner, J., Wirth, J., Lai, J., \& Shott, S. (2006). Relieving symptoms in cancer:Innovative use of art therapy. Journal of Pain and Symptom Management, 31(2), 162169

Nakimuli-Mpungu E, Musisi S, Katabira E, Nachega J, Bass J. (2011). Prevalence and factors associated with depressive disorders in an HIV+ rural patient population in southern Uganda. J Affect Disord; 135(1-3):160-167

Nguyen JT. (2003). The effect of music therapy on end-of-life patients' quality of life, emotional state, and family satisfaction as measured by self-report. Master's Thesis, Florida State University. Florida,.

Pavlicevic, M. (1997). Music therapy in context. London: Jessica Kingsley Publishers

Perry S. (1990). Organic mental disorders caused by HIV: update on early diagnosis and treatment. Am J Psychiatry;147:696-710.

Rao D, Nainis N, Williams L, Langnerc D, Eisinb A, Paiced J. (2009). Art therapy for relief of symptoms associated with HIV/AIDS : AIDS Care; 21(1) 64-69.

Reid S, Dwyer J. (2005). Insomnia in HIV infection: a systematic review of prevalence, correlates, and management. Psychosom Med; 67:260-9. 


\section{Psychological Dimension of HIV/AIDS and Recent Advances in Its Management}

Rihs TA, Begley K, Smith DE, Sarangapany J, Callaghan A, Kelly M, Post JJ, Gold J. (2006). Efavirenz and chronic neuropsychiatric symptoms: a cross-sectional case control study. HIV Med;7(8):544-8.

Safren SA, O'Cleirigh CM, Bullis JR, Otto MW, Stein MD, Pollack MH. (2012). Cognitive behavioral therapy for adherence and depression (CBT-AD) in HIV-infected injection drug users: a randomized controlled trial. J Consult Clin Psychol.;80(3):404-15

Sewell DD. (1996). Schizophrenia and HIV. Schizophr Bull;22(3):465- 73.

Sikkema, K. J., Watt, M. H., Drabkin, A. S., Meade, C. S., Hansen, N. B., \& Pence, B. W. (2010). Mental health treatment to reduce HIV transmission risk behavior: A positive prevention model. AIDS \& Behavior, 14(2), 252-262

Simonton, O.C., Matthews-Simonton, S. and Creighton, J. (1978) Getting Well Again (J.B. Tarcher, Los Angeles)

Sinha UK. Kumar D. (2010). Mindfulness-based Cognitive Behaviour Therapy with Emotionally disturbed Adolescents affected by HIV/AIDS. J. Indian Assoc. Child Adolesc. Ment. Health; 6(1):19-30

Sonneville R, Ferrand H, Tubach F, Roy C, Bouadma L, Klein IF, Foucrier A, Regnier B, Mourvillier B, Wolff . (2011). Neurological complications of HIV infection in critically ill patients: clinical features and outcomes.J Infect; 62(4):301-8.

Taylor, D.N. (1995) "Effects of a behavioral stress-management program on anxiety, mood, selfesteem, and T-cell count in HIV positive men”, Psychol. Rep. 76, 451-457

Thompson, R.J., Gil, K.M., Abrams, M.R., \& Phillips,G. (1992). Stress, coping, and psychological adjustment of adults with sickle cell disease. Journal of Consulting and Clinical Psychology, 60, 433-440.

Timothy G. Heckman, Bernadette D. Heckman, Timothy Anderson, Travis I. Lovejoy, David Mohr, Mark Sutton, Joseph A. Bianco, and Jen-Tzer Gau (2013). Supportive-Expressive and Coping Group Teletherapies for HIV-Infected Older Adults: A Randomized Clinical Trial. AIDS Behav; 17(9)

Treisman, Glenn J., Andrew F. Angelino, and Heidi E. Hutton. "Psychiatric Issue in the Management of Patients with HIV Infection.” Journal of the American Medical Association286, no. 22 (21 December 2001):2857-2864.

UNAIDS (2010) 'UNAIDS report on the global AIDS epidemic'

WHO (2011) 'Global HIV/AIDS Response: Epidemic update and health sector progress towards Universal Access: Progress report 2011' 16.

Wlodarczyk N. (2007). The effect of music therapy on the spirituality of persons in an in-patient hospice unit as measured by self-report. Master's Thesis, Florida State University. Florida 